\title{
Time Trends: A Ten Years Comparison (2005/2006-2015/2016) of Alcohol Misuse During First Year in Medical School
}

\author{
RAZVAN MIHAI HORHAT ${ }^{1 \#,}$ RADU-VASILE BAGIÜ\#, BRIGITHA VLAICU², DELIA HUTANU³, DELIA - IOANA HORHAT2*, \\ LUMINITA NICA ${ }^{1}$, DANIELA IACOB ${ }^{4}$, SMARANDA ARGHIRESCU2*, IULIA-CRISTINA BAGIU² \\ 'Victor Babes University of Medicine and Pharmacy Timisoara, Faculty of Dental Medicine, 2 Eftimie Murgu Sq., 300041, Timisoara, \\ Romania \\ 2Victor Babes University of Medicine and Pharmacy, Faculty of General Medicine, 2 Eftimie Murgu Sq., 300041, Timisoara, \\ Romania \\ ${ }^{3}$ West University of Timisoara, Faculty of Chemistry, Biology Geography, 4 Vasile Parvan Blvd., 300223, Timisoara Romania \\ ${ }^{4}$ Victor Babes University of Medicine and Pharmacy, Department of Neonatology, 2 Eftimie Murgu Sq., 300041, Timisoara, \\ Romania
}

The purpose of the present study was to explore time-trends (2005/2006-2015/2016) of alcohol misuse in first year medical students and types of alcohol preferred by young adults in the same medical school. The study compared two cross-sectional cohorts of medical students (2005/2006: 365 females and 249 males; 2005/2016: 336 females and 123 males) from Timisoara, Romania, using the same questionnaire in both investigations. The analysis was conducted measuring gender and cohort effect on frequency of alcohol use patterns during the last month and the type of alcohol used preferred. Girls have increased with a small effect size both the number of days consuming at least one portion of alcohol and the number of days with binge drinking between evaluations, reducing the gap between boys and girls, seen in 2005/2006 evaluation. In multivariate models, though beer consumption has decreased $(O R=0.6)$ between evaluations, wine $(O R=3.6)$ and spirits $(O R=1.6)$ consumption has increased. Beer and spirits are the type of alcohol used by young people for binge drinking. Interventions to reduce misuse of alcohol in general population or specific to university students need to be carefully tailored to the shifting patterns of alcohol consumption, which are gender specific.

Keywords: Alcohol misuse; Type of alcohol; Binge drinking; Intoxication; Medical students

The term misuse of alcohol is defined by frequent patterns of consume and high volume of consumption, both of which determine the impact of alcohol consumption on acute and chronic health problems. According to W HO, the European Region, especially the Eastern Europe has the highest proportion morbidity and premature death in the world due to misuse of alcohol. The trends of alcohol consumption per capita in the European Region have recorded a negative trend from 11.9 liters of pure alcohol in 2003-2005 to 10.9 liters of pure alcohol in 2008-2010. For Romania, in the same time frame the per capita alcohol consumption has increased from 12.8 to $14.4 \mathrm{~L}$ [1].

Following adolescence, the period of emerging young adulthood is characterized by gaining more independence and exploring various life possibilities [2]. For emerging young adults, especially the first year students, this period represents an abrupt transition to a more independent life with a change in role and setting [3,4]. Several studies have reported for this age an increase of several health risk behaviors, including alcohol abuse and subsequentalcoholrelated problems, such as injuries, crimes [5-7], STDs, unplanned pregnancies, behavioral problems [8] and dependency, co-use of other drugs.

The purpose of the present study was to explore timetrends (2005/2006-2015/2016) of alcohol use and misuse in firstyear medical students and types of alcohol preferred by young adults.

\section{Experimental part \\ Material and Methods \\ Subjects \\ This sample compared two cross-sectional cohorts from 2005/2006 and 2015/2016. Participants were selected from}

the students attending the first year of Victor Babes University of Medicine and Pharmacy Timisoara, that included the following specializations:General Medicine, Dentistry, Nurses and Midwifes. All participants were over 18 years of age at the time of the evaluation, with an age range of 18 - 25 years and median of 20 for the 2006 cohort and an age range of $18-26$ years and median of 21 years for the 2016 cohort. In both occasions students were included in the cohort after expressing their free will to participate. The research was carried out in compliance with Helsinki Declaration.

\section{Questionnaire}

A 126-item questionnaire was developed in 2004 to investigate health-risk behaviors of young adults, as part of the grant The evaluation of risk behavior dimension in high school students and young people from vocational schools and universities in Timis County (CORT 2004), carried out between 2003-2006, CNCSIS code 1167, attained at Victor Babes University of Medicine and Pharmacy Timisoara. Some of the questionnaire items were modified from other instruments, including the Youth Risk Behavior Survey (YRBS) [9] and European School Survey Projecton Alcohol and Other Drugs (ESPAD) [10]. In 2004 a pilot test was conducted to establish the validity and reliability of the instrument. This study received the University's Ethic Committee approval on both occasions.

The questionnaire was administered in both evaluations 2005/2006 and 2015/2016 in a regular classroom/ laboratory/clinical setting and took students $60 \mathrm{~min}$ to complete. No filter questions were used. By doing this, comparable amounts of time are required to complete the

*e-mail:deliahorhat@yahoo.com;Phone:0722281483; sarghirescu@yahoo.com;Phone:0722701837 \#Authors with equal contributions 
questionnaire, regardless of risk behavior status and students cannot detect the risk behaviors of their colleagues simply by looking at the pattern of the responses. Only students present the day of the survey were eligible for participation.

Trained public health residents and undergraduate students conducted the survey. The data collectors read aloud scripts that explained the survey procedures. Anonymity was guaranteed and students were reassured that the information obtained would be used only for general assessment of the situation in the county.

The present paper used questions related to patterns of alcohol consumption during last 30 days: at least one portion and binge drinking, and types of alcohol preferred to consume.

\section{Results and discusions}

Consumes at least one portion of alcohol during lastmonth

For men, 66.9\% (166) in 2006 and 69.9\% (86) in 2016 admit having at least one drink during last month. The percentages for women that consumed at leastone portion of drink during last month are $38.5 \%$ (140) in 2006 and $52.0 \%$ (172) in 2016. In both evaluations, boys had consumed at least one portion of alcohol in significantly more days than the girls, with a medium effect size in 2005/2006: $U=28919, z=-8.17, p<0.001, r=0.33$, and $a$ small effect size for 2015/2016 sample: $U=14701, z=-$ 4.84, $p<0.001, r=0.22$.

Between evaluations, boys did not significantly modify the proportion of days with at least one portion of alcohol, but for girls, the number of days had increased between evaluations: $U=51783.5, z=-3.56, p<0.001, r=0.14$, with a small effect size (table 1 ).

\section{Practices binge drinking during last month}

Regarding binge drinking, for 2006, 35.1\% (87) of men and $8.9 \%$ (36) of women admit they consumed at least in one occasion 5 or more portions of alcohol. For 2016 the percentages of students practicing binge drinking are $31 \%$ (50) for men and $16 \%$ (53) for women. In both evaluations, boys binge drank in significantly more days than the girls, with a medium effect size in 2005/2006: $U=33340.5$, $z=-$ $7.85, p<0.001, r=0.32$, and a small to medium effect size for 2015/2016 sample: $U=14925, z=-5.86, p<0.001$, $r=0.27$.

Also for binge drinking in boys group no significant differences were found betw een evaluations regarding the number of days during last month when they drank more than 5 portions of alcohol in an occasions, $p=0.157$, but girls significantly increased the number of days with binge drinking $U=56565, z=-2.51, p=0.012, r=0.09$, with a small effect size (Table 2).

\section{Type of preferred alcoholic beverage}

In 2005/2006 evaluation $73.5 \%$ of men (183) and $52.9 \%$ (192) of women answered the question regarding the type of alcohol consumed. For the 2016 evaluation, the percentages of men declaring the type of alcohol preferred are $78.0 \%$ (96) for men and $64.5 \%$ (213) for women (table 3).

\begin{tabular}{|c|c|c|c|c|c|c|c|c|}
\hline \multirow{3}{*}{$\begin{array}{l}\text { Consumes at least } \\
\text { one portion of } \\
\text { alcohol during last } \\
\text { month }\end{array}$} & \multicolumn{4}{|c|}{2006} & \multicolumn{4}{|c|}{2016} \\
\hline & \multicolumn{2}{|l|}{$\mathrm{F}$} & \multicolumn{2}{|l|}{ M } & \multicolumn{2}{|l|}{ F } & \multicolumn{2}{|c|}{ M } \\
\hline & $\underset{\%}{\text { Column }} \mathrm{N}$ & Count & Column $\mathrm{N}$ & Count & Column $\mathrm{N}$ & Count & Column $N$ & Count \\
\hline Never & $61.5 \%$ & 224 & $33.1 \%$ & 82 & $48.0 \%$ & 159 & $30.1 \%$ & 37 \\
\hline $1-5$ days & $33.2 \%$ & 121 & $47.2 \%$ & 117 & $44.4 \%$ & 147 & $47.2 \%$ & 58 \\
\hline $\begin{array}{l}6 \text { or more } \\
\text { days }\end{array}$ & $5.2 \%$ & 19 & $19.8 \%$ & 49 & $7.6 \%$ & 25 & $22.8 \%$ & 28 \\
\hline Subtotal & $100.0 \%$ & 364 & $100.0 \%$ & 248 & $100.0 \%$ & 331 & $100.0 \%$ & 123 \\
\hline
\end{tabular}

Table 1

DISTRIBUTION OF PARTICIPANTS ACCORDING TO CONSUME OF AT LEAST ONE PORTION OF ALCOHOL DURING LAST MONTH

\begin{tabular}{|c|c|c|c|c|c|c|c|c|}
\hline \multirow{3}{*}{\begin{tabular}{|l} 
Practices binge \\
drinking during last \\
month
\end{tabular}} & \multicolumn{4}{|c|}{2006} & \multicolumn{4}{|c|}{2016} \\
\hline & \multicolumn{2}{|l|}{$\mathrm{F}$} & \multicolumn{2}{|l|}{ M } & \multicolumn{2}{|l|}{$\mathrm{F}$} & \multicolumn{2}{|l|}{ M } \\
\hline & $\begin{array}{l}\text { Column N } \\
\%\end{array}$ & Count & $\begin{array}{l}\text { Column N } \\
\%\end{array}$ & Count & $\begin{array}{l}\text { Column N } \\
\%\end{array}$ & Count & $\begin{array}{l}\text { Column N } \\
\%\end{array}$ & Count \\
\hline Never & $90.1 \%$ & 328 & $64.9 \%$ & 161 & $84.0 \%$ & 279 & $59.0 \%$ & 72 \\
\hline $1-5$ days & $9.9 \%$ & 36 & $31.0 \%$ & 77 & $14.2 \%$ & 47 & $34.4 \%$ & 42 \\
\hline $\begin{array}{l}6 \text { or more } \\
\text { days }\end{array}$ & $0.0 \%$ & 0 & $4.0 \%$ & 10 & $1.8 \%$ & 6 & $6.6 \%$ & 8 \\
\hline Subtotal & $100.0 \%$ & 364 & $100.0 \%$ & 248 & $100.0 \%$ & 332 & $100.0 \%$ & 122 \\
\hline
\end{tabular}

Table 2

DISTRIBUTION OF PARTICIPANTS ACCORDING TO PRACTICING BINGE DRINKING DURING LAST MONTH

\begin{tabular}{|c|c|c|c|c|c|c|c|c|}
\hline \multirow{3}{*}{$\begin{array}{l}\text { Type of favorite } \\
\text { alcoholic beverage }\end{array}$} & \multicolumn{4}{|l|}{2006} & \multicolumn{4}{|l|}{2016} \\
\hline & \multicolumn{2}{|l|}{$\mathrm{F}$} & \multicolumn{2}{|l|}{ M } & \multicolumn{2}{|l|}{$\mathrm{F}$} & \multicolumn{2}{|l|}{ M } \\
\hline & Count & $\begin{array}{l}\% \\
\text { per } \\
\text { layer }\end{array}$ & Count & $\begin{array}{l}\% \\
\text { per } \\
\text { layer }\end{array}$ & Count & $\begin{array}{l}\% \\
\text { per } \\
\text { layer }\end{array}$ & Count & $\begin{array}{l}\% \\
\text { per } \\
\text { layer }\end{array}$ \\
\hline Beer & 104 & 54.17 & 137 & 74.86 & 75 & 35.21 & 69 & 71.88 \\
\hline Wine & 128 & 66.67 & 94 & 51.37 & 163 & 76.53 & 64 & 66.67 \\
\hline Spirits & 14 & 7.29 & 40 & 21.86 & 57 & 26.76 & 43 & 44.79 \\
\hline
\end{tabular}

Table 3

DISTRIBUTIONS OF PARTICIPANTS ACCORDING TO THE FAVORITE TYPE OF ALCOHOLIC BEVERAGE 
In 2005/2006, higher proportions of men, compared to women consume beer $\chi^{2}(1)=43.89, p<0.001,0 R=3.09$, IC95\% $=(2.202 ; 4.336)$, and spirits $\chi^{2}(1)=27.60, p<0.001$, $\mathrm{OR}=4.80, \mathrm{IC} 95 \%=(2.552 ; 9.041)$, but equal proportions consume wine, $p=0.497$.

In 2015/2016 evaluation, the results are similar, higher proportions of men, compared to women consume beer $\chi^{2}(1)=46.01, p<0.001, O R=4.344, I C 95 \%=(2.800 ; 6.742)$, and spirits $\chi^{2}(1)=16.29, \quad p<0.001, \quad O R=2.57$, IC95\%=(1.613; 4.110), but equal proportions consume wine, $p=0.617$.

The proportion of beer consumers is constant between evaluations, for both men $(p=0.908)$ and women $(p=0.072)$. Instead, the proportion of wine consumers has increased for both men $\chi^{2}(1)=6.55, p=0.010, O R=1.76$, IC $95 \%=(1.140 ; 2.734)$ and women $\chi^{2}(1)=13.95, p<0.001$, $\mathrm{OR}=1.78, \mathrm{IC} 95 \%=(1.315 ; 2.421)$.

Also, the spirits consumers proportion has increased for both men $\chi^{2}(1)=16.61, p<0.001, O R=2.78, I C 95 \%$ $=(1.684 ; 4.595)$ and women $\chi^{2}(1)=33.69, p<0.001$, $\mathrm{OR}=5.19, \mathrm{IC} 95 \%=(2.832 ; 9.511)$.

\section{Predictions}

Direct logistic regression was performed in order to assess the impact of gender, group and pattern of alcohol consume during last month on the likelihood that the respondents would answer that they prefer to consume beer, vine or spirits.

Each of the models was applied separately for each type of preferred alcoholic drink. Each model contained 6 independent variables [gender (M/F), group (2005/2006 and for 2015/2016), frequency of alcohol consumption at least one portion ( 0 days, 1-5 days, over 6 days), frequency of binge drinking ( 0 days, 1-5 days, over 6 days) both during last month].

For beer the full model containing all predictors was statistically significant, $\chi^{2}(6, N=1074)=305.9, p<0.001$, indicating that the model was able to distinguish between respondents who had beer as their favorite alcoholic drink or not. The model as a whole explained between $25.1 \%$ and $34.4 \%$ of the variance of having beer as their favorite alcoholic drink or not, and correctly classified $75.4 \%$ of cases. All six predictors made a unique contribution to the model. The strongest predictor of having beer as favorite alcoholic beverage was the daily consumption of at least one portion of alcohol in more than 5 days during last month, as compared who students who did not consume at least one portion of alcohol during last month, which recorded a $\mathrm{OR}=7.6$. Students who drank in 1 to 5 days at least one portion of alcohol had 5 times more chances to like beer (table 4).

Students who practiced binge drinking in more than 6 days during last month, as compared to those who did not practice binge drinking at all, had an $\mathrm{OR}=5.1$ and students who practiced binge drinking in 1 to 5 days during last month had an $\mathrm{OR}=2.3$. Boys were 2.2 times more likely to preferred beer, as compared to girls. The sample 2015/2016 had an $O R=0.604$ meaning that the sample in 2015/2016 consumed significantly less beer than the sample from $2005 / 2006$ For wine the full model containing all predictors was statistically significant, $\chi^{2}(6, N=1074)=221.2$, $p<0.001$, indicating that the model was able to distinguish between respondents who had wine as their favorite alcoholic drink or not. The model as a whole explained between $18.8 \%$ and $25.3 \%$ of the variance of having wine as their favorite alcoholic drink or not, and correctly classified $71.8 \%$ of cases. Only three predictors made a unique contribution to the model. The strongest predictor of having wine as favorite alcoholic beverage was the daily consumption of at least one portion of alcohol in 1 to 5 days during last month, as compared who students which did not drink alcohol at least one portion, which recorded a $\mathrm{OR}=7.8$. Students who drank in more than 6 days at least one portion of alcohol had 7.3 times more chances to like wine. The group of 2015/2016 was 1.6 times more likely to consume wine, compared to group investigated in 2005/ 2006. For gender, the $\mathrm{OR}=0.706$ indicating that women are more likely than men to prefer wine.

The frequency of binge drinking did not contribute to the model (table 5).

For spirits, the full model containing all predictors was statistically significant, $\chi^{2}(6, N=1074)=181.4, p<0.001$, indicating that the model was able to distinguish between respondents who had wine as their favorite alcoholic drink or not. The model as a whole explained between $15.7 \%$ and $28.0 \%$ of the variance of having wine as their favorite alcoholic drink or not, and correctly classified $86.6 \%$ of cases. All 6 predictors made a unique contribution to the model. The strongest predictor of having spirits as favorite alcoholic beverage was the frequency of binge drinking of more than 6 days during last month, which recorded an $\mathrm{OR}=5.8$. The frequency of binge drinking of 1 to 5 days had an $O R=3.77$.

Table 4

PREDICTORS OF HAVING BEER AS FAVORITE ALCOHOLIC BEVERAGE

\begin{tabular}{|c|c|c|c|c|c|c|c|c|}
\hline \multirow{2}{*}{$\begin{array}{l}\text { Predictors of having beer as favorite } \\
\text { alcoholic beverage }{ }^{\text {a }}\end{array}$} & \multirow[t]{2}{*}{ B } & \multirow[t]{2}{*}{ S.E. } & \multirow[t]{2}{*}{ Wald } & \multirow[t]{2}{*}{ df } & \multirow[t]{2}{*}{ Sig. } & \multirow[t]{2}{*}{$\operatorname{Exp}(B)$} & \multicolumn{2}{|c|}{$95 \%$ C.I.for EXP(B) } \\
\hline & & & & & & & Lower & Upper \\
\hline $\operatorname{Sex}(M$ vs. F) & .794 & .158 & 25.320 & 1 & .000 & 2.211 & 1.623 & 3.012 \\
\hline $\begin{array}{l}\text { Group } \\
2005 / 2006)\end{array}$ & -.508 & .157 & 10.520 & 1 & .001 & .602 & $.443^{--}$ & .818 \\
\hline $\begin{array}{l}\text { No of days with at least } 1 \text { portion of } \\
\text { alcohol }\end{array}$ & & & 94.007 & 2 & .000 & & & \\
\hline $1-5$ days vs. 0 days & 1.612 & .177 & 83.367 & 1 & .000 & 5.013 & 3.546 & 7.085 \\
\hline Over 6 days vs. 0 days & 2.023 & .284 & 50.905 & 1 & .000 & 7.563 & 4.338 & 13.184 \\
\hline No of Days with binge drinking & & & 20.585 & 2 & .000 & & & \\
\hline $1-5$ days vs. 0 days & .823 & .198 & 17.328 & 1 & .000 & 2.276 & 1.545 & 3.353 \\
\hline Over 6 days vs. 0 days & 1.633 & .675 & 5.855 & 1 & .016 & 5.118 & 1.364 & 19.208 \\
\hline Constant & -1.894 & .152 & 154.449 & 1 & .000 & .150 & & \\
\hline
\end{tabular}

a. Variables entered on step 1: sex, group, No of days with at least 1 portion of alcohol, No of Days with binge drinking. 
Table 5

PREDICTORS OF HAVING WINE AS FAVORITE ALCOHOLIC BEVERAGE

\begin{tabular}{|c|c|c|c|c|c|c|c|c|}
\hline \multirow{2}{*}{$\begin{array}{l}\text { Predictors of having wine asfavonte alcoholic } \\
\text { beverage }^{\text {a }}\end{array}$} & \multirow[t]{2}{*}{ B } & \multirow[t]{2}{*}{ S.E. } & \multirow[t]{2}{*}{ Wald } & \multirow[t]{2}{*}{ df } & \multirow[t]{2}{*}{ Sig. } & \multirow[t]{2}{*}{$\operatorname{Exp}(B)$} & \multicolumn{2}{|c|}{ 95\% C.I.for EXP(B) } \\
\hline & & & & & & & Lower & Upper \\
\hline Sex (M vs. F) & -.348 & .157 & 4.920 & 1 & .027 & .706 & .519 & .960 \\
\hline Group $(2015 / 2016$ vs. $2005 / 2006)$ & .504 & .142 & 12.586 & 1 & .000 & 1.656 & 1.253 & 2.188 \\
\hline No of days with at least 1 portion of alcohol & & & 156.925 & 2 & .000 & & & \\
\hline $1-5$ days vs. 0 days & 2.049 & .165 & 153.836 & 1 & .000 & 7.756 & 5.611 & 10.721 \\
\hline Over 6 days vs. 0 days & 1.988 & .265 & 56.201 & 1 & .000 & 7.304 & 4.343 & 12.283 \\
\hline No of Days with binge drinking & & & 1.620 & 2 & .445 & & & \\
\hline $1-5$ days vs. 0 days & -.244 & .192 & 1.619 & 1 & .203 & .783 & .538 & 1.141 \\
\hline Over 6 days vs. 0 days & -.166 & .480 & .119 & 1 & .730 & .847 & 330 & 2.173 \\
\hline Constant & -1.512 & .136 & 123.478 & 1 & .000 & .221 & & \\
\hline
\end{tabular}

a. Variables entered on step 1: sex, group, No of days with at least 1 portion of alcohol, No of Days with binge drinking.

Table 6

PREDICTORS OF HAVING SPIRITS AS FAVORITE ALCOHOLIC BEVERAGE

\begin{tabular}{|c|c|c|c|c|c|c|c|c|}
\hline \multirow{2}{*}{$\begin{array}{l}\text { Predictors of having spirits as favorite } \\
\text { alcoholic beverage }{ }^{\text {a }}\end{array}$} & \multirow[t]{2}{*}{ B } & \multirow[t]{2}{*}{ S.E. } & \multirow[t]{2}{*}{ Wald } & \multirow[t]{2}{*}{ df } & \multirow[t]{2}{*}{ Sig. } & \multirow[t]{2}{*}{$\operatorname{Exp}(B)$} & \multicolumn{2}{|c|}{ 95\% C.I.for EXP(B) } \\
\hline & & & & & & & Lower & Upper \\
\hline Sex (M vs. F) & .639 & .211 & 9.136 & 1 & .003 & 1.895 & 1.252 & 2.868 \\
\hline $\begin{array}{l}\text { Group } \\
2005 / 2006)\end{array}$ & 1.272 & .209 & 37.175 & 1 & $.000^{-}$ & 3.569 & 2.371 & 5.373 \\
\hline No of days with at least 1 portion of alcohol & & & 13.928 & 2 & .001 & & & \\
\hline $1-5$ days vs. 0 days & .885 & .272 & $10.580^{-}$ & 1 & .001 & 2.424 & 1.422 & 4.132 \\
\hline Over 6 days vs. 0 days & 1.252 & .357 & 12.283 & 1 & $.000^{-}$ & 3.497 & $1.736^{-}$ & 7.044 \\
\hline No of Days with binge drinking & & & 34.810 & 2 & .000 & & & \\
\hline $1-5$ days vs. 0 days & 1.329 & $.235^{-}$ & 32.033 & 1 & .000 & 3.775 & 2.383 & 5.981 \\
\hline Over 6 days vs. 0 days & 1.754 & .514 & 11.666 & 1 & .001 & 5.778 & 2.112 & 15.809 \\
\hline Constant & -3.848 & .270 & 202.400 & 1 & .000 & .021 & & \\
\hline
\end{tabular}

a. Variables entered on step 1: sex, group, No of days with at least 1 portion of alcohol, No of Days with binge

Students enrolled in 2015/2016 were 3.6 more likely than the students evaluated in 2005/2006 and men were 1.9 times than women to drink spirits.

Students who drank in more than 6 days at least one portion of alcohol had 3.5 times more chances to like spirits. Daily consumption of at least one portion of alcohol in 1 to 5 days during last month, as compared who students which did nothave any day during lastmonth when they consumed one portion of alcohol, recorded an $\mathrm{OR}=2.4$ (table 6).

The prevalence of use of alcohol, defined as the consume at a least a portion of alcohol during last month for 2005/ 2006 sample of $66.9 \%$ for men and $38.5 \%$ for women and for $2015 / 2016$ sample of $69.9 \%$ for men and $52.0 \%$ for women. This study has found that, in men, 35\% in 2005/ 2006 and $41 \%$ in $2015 / 2016$ practiced binge drinking, while in women $9.9 \%$ in 2005/2006 and $16 \%$ in 2015/2016 had this pattern of consumption.In men, the number of days during last month with at least one portion of alcohol and the number of days with binge drinking was kept relatively constant between evaluations, but women have increased both the number of days in which consumed at least a portion of alcohol and in which binge drank, with a small effect size, reducing the gap between men and women. WHO recommend at most $20 \mathrm{~g}$ of alcohol per day for man and $10 \mathrm{~g}$ of alcohol for women, but not in all days, and in the absence of binge drinking [1]. Most beneficial health effect related to coronary artery disease [11], cardiovascular and overall mortality [12] were seen in elderly moderate drinkers. For internalizing disorders such as depression or anxiety, in young people [13], or for breast cancer in women [14] no beneficial effects were observed even in low doses of alcohol. Instead heavy drinking was associated in several cohorts with increase mortality and morbidity, and according to WHO the percentage of alcohol-attributable deaths among men amount to $7.6 \%$ of all global deaths compared to $4.0 \%$ of all deaths among women [1]. In both evaluations, for men beer remains top favorite alcoholic drink, followed by wine, and then spirits, while for women wine is top favorite alcoholic drink, followed by beer and spirits. The proportions of each type of alcohol have changed as follows: while beer consumption maintained constantfor both genders, wine and spirits have increased their quotation as favorite in 2015/2016 evaluation.The prediction model for beer indicated that the consumer was male, which consumed it in at least as portion throughout the last month, but also used it for binge drinking, with a predilection of belonging to 2005/2006 evaluation. In prediction model for wine significant contributors were feminine gender, and 2015/2016 evaluation, and moderate consumption. Binge drinking patterns did not contribute significantly to prediction of wine 
as favorite drink. For spirits, the user profile is of masculine gender, with membership in 2015/2016 evaluation, binge drinker, but also moderate consumer.

So the pattern of consumption related to type of alcohol has shifted: in 2005/2006 beer was used for binge drinking, while in 2015/2016 the odds ratio for spirits have increased. Most probably spirits are consumed hidden in fixed drinks such as alcopop or mixed with energy drinks, which contain high amounts of sugar and hide the strong taste of this type of alcoholic drink.

A recent review [15] of 62 studies has shown that young people who consumed mixes of alcohol-energy drinks have drank more alcohol and experienced more alcohol-related harm than other users.

Beneficial effect of wine and beer is due to non-alcoholic compounds, manly polyphenols, found in higher quantities in wine, compared to beer. In a review, Arranz et al [16] have pointed out that regular and moderate wine and beer consumption is associated with decreased incidence of cardiovascular disease (CVD), hypertension, diabetes, and certain types of cancer, including colon, basal cell, ovarian, and prostate carcinoma, the effect being lower for beer. Recent study [17] showed a beneficial effect in moderate beer consumption for major chronic conditions and some benefit against cardiovascular disease. Other authors [18] have shown a reduction of the endothelial dysfunction associated with cardiovascular risk factors by nonalcoholic beer components.

On the other hand, spirits have the lowest amount of polyphenols of all alcoholic beverages.

\section{Conclusions}

The present study gives a unique overview of the changing trends in type and patterns of use and misuse of alcohol in medical students from western Romania, over one decade. The prevalence of use of alcohol, defined as the consume at a least a portion of alcohol during last month for $2005 / 2006$ sample of $66.9 \%$ for men and $38.5 \%$ for women and for $2015 / 2016$ sample of $69.9 \%$ for men and $52.0 \%$ for women. This study has found that, in men, $35 \%$ in 2005/2006 and 41\% in 2015/2016 practiced binge drinking, while in women $9.9 \%$ in 2005/2006 and $16 \%$ in $2015 / 2016$ had this pattern of consumption.In men, the number of days during last month with at least one portion of alcohol and the number of days with binge drinking was kept relatively constant between evaluations, but women have increased both the number of days in which consumed at leasta portion of alcohol and in which binge drank, with a small effect size, reducing the gap between men and women.

In both evaluations, for men beer remains top favorite alcoholic drink, followed by wine, and then spirits, while for women wine is top favorite alcoholic drink, followed by beer and spirits. The proportions of each type of alcohol have changed as follows: while beer consumption maintained constantfor both genders, wine and spirits have increased their quotation as favorite in 2015/2016 evaluation.

\section{References}

1.***WHO. Global status report on alcohol and health - 2014 ed. Accesed at http://www.who.int/substance_abuse/publications/ global_alcohol_report/en/, 23.08.16

2.ARNETT, J EFFREY JENSEN, Emerging adulthood: A theory of development from the late teens through the twenties. American Psychologist. 2000, 55 (5): 469-480. doi:10.1037/0003-066X.55.5.469.3.
3. HORHAT, R.M., VLAICU, B., BAGIU, R., et al., A Ten-year Time Laps, Regarding Drug Consumption in the Western Part of Romania, Rev.Chim.(Bucharest), 69, no. 6, 2018, p.1371-1375

4.U. BRONFENBRENNER, The ecology of human development: Experiments by nature and design. Harvard University Press, Cambridge, MA (1979)

5.JOSEPH M. BODEN, , DAVID M. FERGUSSON, L. JOHN HORWOOD, Alcohol misuse and criminal offending: Findings from a 30-year longitudinal study. Drug and Alcohol Dependence. Volume 128, Issues 12, 1 February 2013, Pages 30-36

6.BAGIU, I.C., VLAICU, B., ONISEI, D., et al., Types of Alcohol Associated to Binge Drinking Behaviour Among Students from Timis County, Rev.Chim.(Bucharest), 67, no. 9, 2016, p. 1684-1687

7.BAGIU, I., PUTNOKY, S., TUTA-SAS, I., et al., MANIFESTATIONS OF SELF-HARM IN RELATION WITH BINGE DRINKING TO STUDENTSFROM TIMIS COUNTY, ROMANIA, MEDICAL-SURGICAL JOURNAL-REVISTA MEDICO-CHIRURGICALA, Volume: 119 Issue: 4, Pages: 1106-1112 Published: 2015

8.DAVID M. FERGUSSON, JOSEPH M. BODEN, L. JOHN HORWOOD. Alcohol misuse and psychosocial outcomes in young adulthood: Results from a longitudinal birth cohort studied to age 30. Drug and Alcohol Dependence, Volume 133, Issue 2, 1 December 2013, Pages 513-519

9.***, The Youth Risk Behavior Surveillance System, Department of Health and Human Services, Center for Disease Control and Prevention 2005, USA

10. HIBELL B, ANSERSSON B, BJARNASON T, AHLSTRÖM S, BALAKIREVA O, KOKKEVI A, MORGAN M, The ESPAD Report 2003 Alcohol and Other Drug Use Among Students in 35 European Countries, The Swesish Council for Information on Alcohol and Other Drugs, The Pompidou Group at the Council of Europe and the authors, Sweden, 2004,modintryckoffset AB, Stockholm

11.YANG YANG, DONG-CHEN LIU, QI-MING WANG, QING-QING LONG, et al. Alcohol consumption and risk of coronary artery disease: $A$ dose-response meta-analysis of prospective studies. Nutrition. June 2016 Volume 32, Issue 6, Pages 637-644

12.S. COSTANZO, A. DI CASTELNUOVO, M.B. DONATI, L. IACOVIELLO, G. DE GAETANO. Cardiovascular and overall mortality risk in relation to alcohol consumption in patients with cardiovascular disease. Circulation, 121 (17) (2010), pp. 1951-1959

13.JOSEPH M. BODEN, JAMES A. FOULDS, L. JOHN HORWOOD EXamination of a possible J-shaped relationship between alcohol consumption and internalizing disorders in a longitudinal birth cohort. Drug and Alcohol Dependence Volume 162, 1 May 2016, Pages 88-91 14.CHIARA SCOCCIANTI, BEATRICE LAUBY-SECRETAN, PIERRE-YVES BELLO, et al. Female Breast Cancer and Alcohol Consumption: A Review of the Literature. American Journal of Preventive Medicine. Volume 46, Issue 3, Supplement 1, March 2014, Pages S16-S25. Opportunities for Cancer Prevention During Midlif

15.MCKETIN REBECCA, COEN ALICE, KAYE SHARLENE. A comprehensive review of the effects of mixing caffeinated energy drinks with alcoholDrug and Alcohol Dependence. June 2015, Volume 151, 1 Pages 15-30

16.SARA ARRANZ, GEMMA CHIVA-BLANCH, PALMIRA VALDERASMARTÍNEZ, ALEX MEDINA-REMON, ROSA M. LAMUELA-RAVENTÓS AND RAMÓN ESTRUCH. Wine, Beer, Alcohol and Polyphenols on Cardiovascular Disease and Cancer Nutrients 2012, 4(7), 759-781; doi:10.3390/nu4070759

17.DE GAETANOA G, COSTANZO S, DI CASTELNUOVOA A, et al. Effects of moderate beer consumption on health and disease: $A$ consensus document. Nutrition, Metabolism and Cardiovascular Diseases. J une 2016, Volume 26, Issue 6, Pages 443-467, http://dx.doi.org/10.1016/ j.numecd.2016.03.007

18.VILAHUR G, CASANI L, MENDIETA G, et al. Beer elicits vasculoprotective effects through Akt/eNOS activation. Eur J Clin Invest 2014; 44 (12): 1177-1188. DOI: 10.1111/eci.12352 